\title{
Cervical collar makes difficult airway: a simulation study using the LEMON criteria
}

\author{
Moonsu Yuk' ${ }^{1}$, Woonhyung Yeo ${ }^{1}$, Kangeui Lee ${ }^{1}$, Jungin Ko${ }^{2}$, Taejin Park ${ }^{1}$ \\ 'Department of Emergency Medicine, National Medical Center, Seoul, Korea \\ ${ }^{2}$ Department of Emergency Medicine, Seoul National University College of Medicine, Seoul, Korea
}

Objective Endotracheal intubation is extremely difficult to perform in patients wearing a cervical collar for a head and neck injury. Therefore, we analyzed actual measurements using the look externally, evaluate 3-3-2, Mallampati score, obstruction, and neck mobility (LEMON) criteria before and after cervical collar application to investigate the causes of a difficult airway.

Methods This simulation study was performed in 76 healthy volunteers. We measured the mouth opening, modified Mallampati classification, and neck extension before and after cervical collar application.

Results The mean inter-incisor distance significantly decreased from 4.3 to $2.6 \mathrm{~cm}(\mathrm{P}<0.001)$. Fifty-seven participants classified as I and II were newly classified as III and IV according to the modified Mallampati classification after cervical collar application (16\% to 91\%). The angles of neck extension significantly decreased from $44^{\circ}$ to $22^{\circ}$ after cervical collar application $(P<0.001)$. Before cervical collar application, our simulations predicted that 14 of 76 participants (18\%) would have a difficult airway, whereas after cervical collar application, 76 of $76(100 \%)$ were predicted to have a difficult airway.

Conclusion All values for the LEMON criteria (mouth opening, modified Mallampati classification, and neck extension) worsened significantly after cervical collar application. Additionally, a difficult airway was predicted in all participants after cervical collar application.

Keywords Airway management; Difficult airway; Cervical collar; LEMON criteria

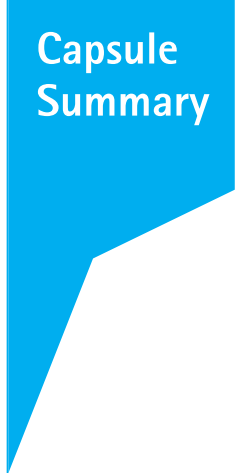

What is already known

Endotracheal intubation is extremely difficult to perform in patients wearing a cervical collar.

What is new in the current study

All measured values (mouth opening, modified Mallampati classification, and neck extension) of the LEMON (look externally, evaluate 3-3-2, Mallampati score, obstruction, and neck mobility) criteria worsened significantly after cervical collar application.
elSSN: 2383-4625

Received: 6 October 2017

Revised: 6 February 2018

Accepted: 14 February 2018

Correspondence to: Taejin Park Department of Emergency Medicine, National Medical Center, 245 Eulji-ro, Jung-gu, Seoul 04564, Korea E-mail: NMCemergency@gmail.com

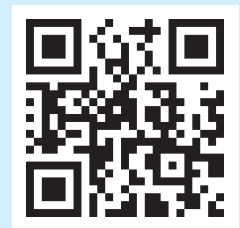

How to cite this article:

Yuk M, Yeo W, Lee K, Ko J, Park T. Cervical collar makes difficult airway : a simulation study using the LEMON criteria. Clin Exp Emerg Med 2018;5(1):22-28.

This is an Open Access article distributed under the terms of the Creative Commons Attribution Non-Commercial License (http:// creativecommons.org/licenses/by-nc/4.0/). 


\section{INTRODUCTION}

According to the advanced trauma life support guidelines, a cervical collar should be applied to trauma patients with head and neck injuries from the time of the incident until exclusion of a cervical injury to prevent permanent neurologic damage. ${ }^{1,2}$ However endotracheal intubation is extremely difficult to perform in patients wearing a cervical collar. ${ }^{3}$ In the clinical setting, direct intubation of a patient wearing a cervical collar could fail. The cervical collar interferes with the optimal intubating condition, i.e., alignment of the oral, pharyngeal, and tracheal axes and sniffing position. ${ }^{4}$ Maneuvers such as manual in-line stabilization (MILS) and novel airway devices have been introduced and compared for managing the difficult airway with a cervical collar. ${ }^{5}$ However, the optimal method is controversial. The purpose of this study was to present a theoretical basis for solving the difficulty resulting from cervical collar application by providing specific data about different airway parameters.

To investigate the causes of a difficult airway, we analyzed parameters of the look externally, evaluate 3-3-2, Mallampati score, obstruction, and neck mobility (LEMON) criteria before and after cervical collar application. ${ }^{6}$

\section{METHODS}

\section{Study design}

This simulation study was conducted at a general hospital from March 2015 to February 2016. The study population included healthy volunteers aged older than 18 years. Eighty-three volunteers who agreed to participate were enrolled, seven of whom were excluded because of a history of cervical operation $(n=2)$, temporomandibular joint disorder $(n=4)$, and recent trauma of the head and neck $(n=1)$ according to our exclusion criteria. Thus, 76 volunteers were enrolled (Fig. 1). All participants provided informed consent and were not provided any compensation for participating in the study. The study protocol was reviewed and approved by the institutional review board (H-1410-047-003).

\section{Simulation methods}

We analyzed differences in the measured LEMON parameters before and after cervical collar application. We chose the following LEMON parameters, which are used to predict a difficult airway: mouth opening, modified Mallampati classification, obesity and neck extension. ${ }^{7,8}$ The mean of the values measured by two different physicians were accepted as the final values. The measurement methods for each parameter are shown in Fig. 2.

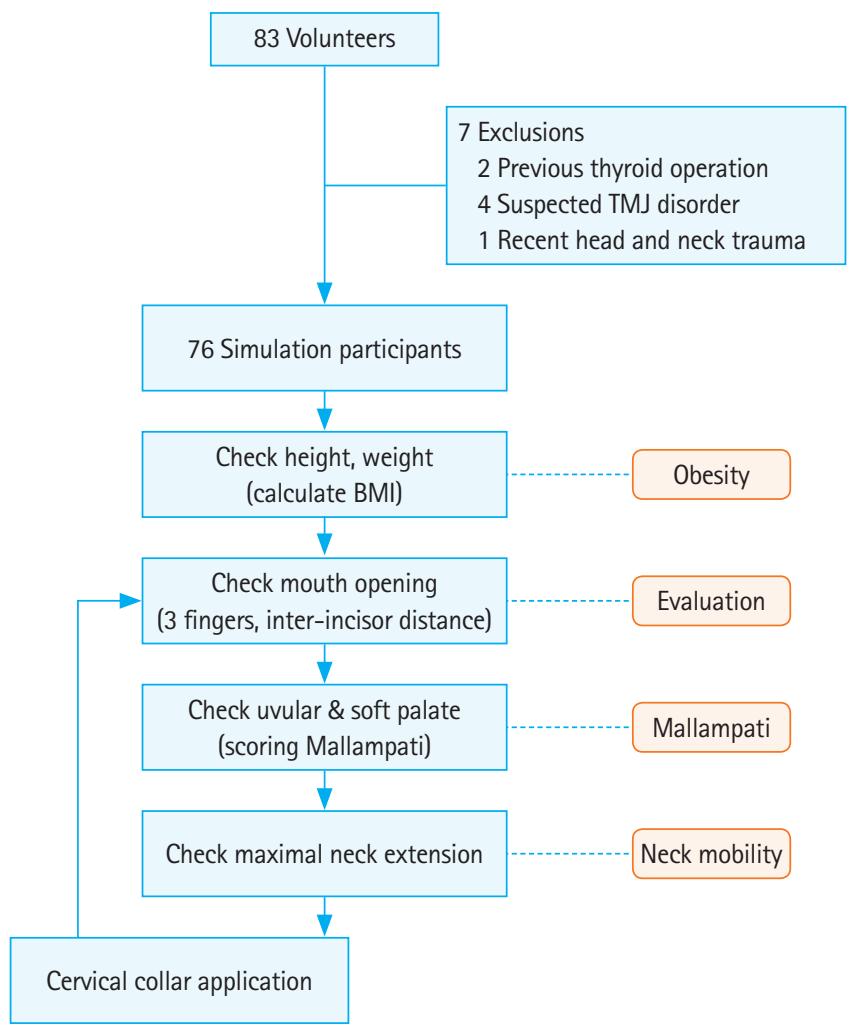

Fig. 1. Study enrollment and methods. TMJ, temporomandibular joint; $\mathrm{BMI}$, body mass index.

\section{Basic body measurements}

An automated height-weight machine was used to measure basic body parameters. The body mass index (BMI) was calculated using the following formula: $\mathrm{BMI}=$ weight $(\mathrm{kg}) \div$ height $^{2}\left(\mathrm{~m}^{2}\right)$.

\section{Mouth opening (3-3-2 evaluation)}

We evaluated whether three fingers could be easily passed into each participant's mouth while they were in a sitting position with maximal mouth opening. The value of one's inter-incisor distance (i.e., from the lower border of the upper incisors to the upper border of the lower incisors) was also measured using vernier calipers.

\section{Modified Mallampati classification}

The modified Mallampati classification is a visual assessment of the distance from the tongue base to the roof of the mouth. Participants were instructed to open their mouths as wide as possible and to protrude their tongue to a maximum while in the sitting position. The airway was classified in accordance with the pharyngeal structures seen: class I, soft palate, fauces, uvula, and pillars; class II, soft palate, fauces, and uvula; class III, soft palate and base of the uvula; and class IV, soft palate not visible at all. ${ }^{9}$ 

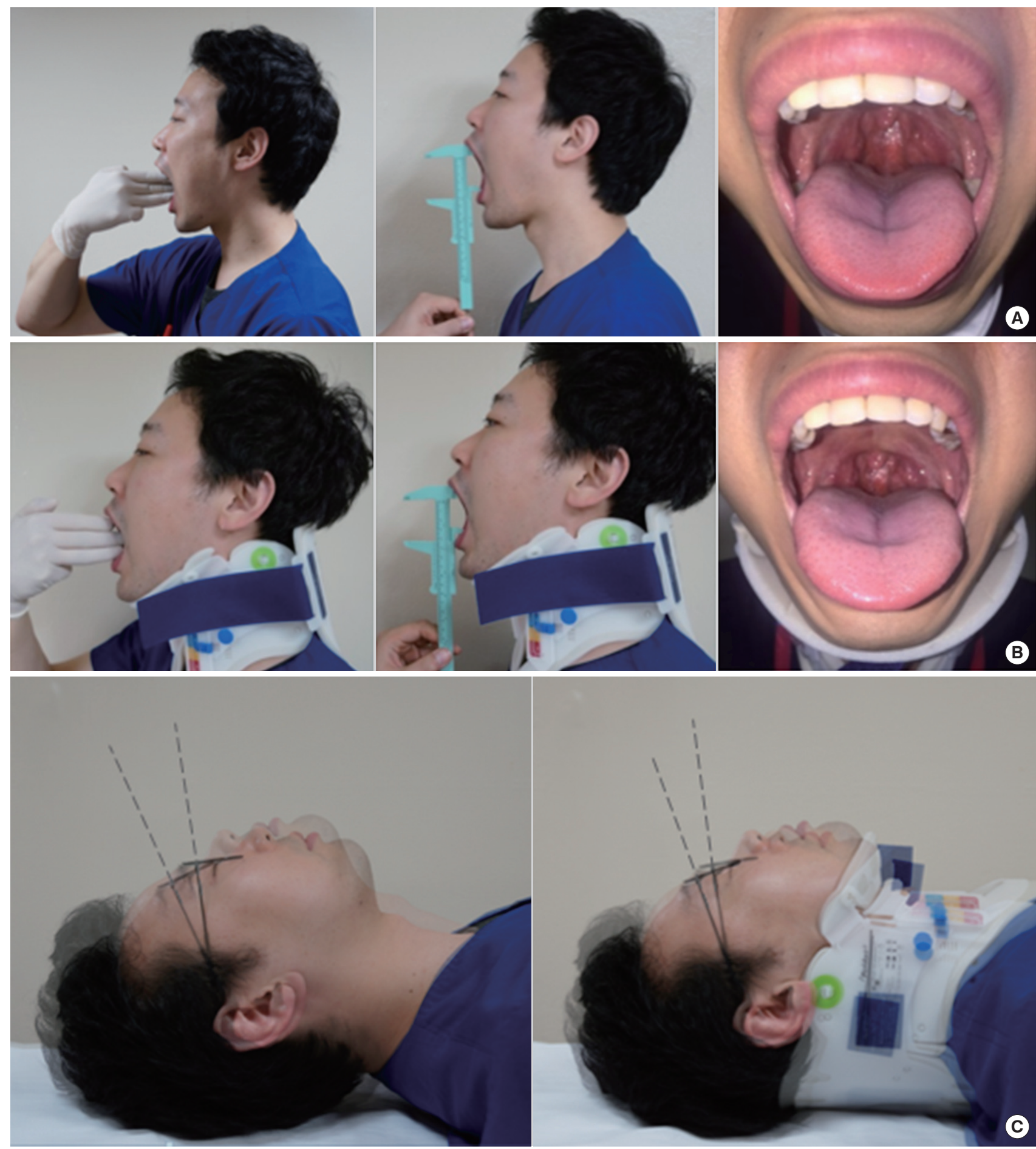

Fig. 2. Measurement methods for mouth opening, Mallampati score, and degree of neck extension with and without the cervical collar. (A) Measurement methods for evaluating mouth opening and Mallampati score without the cervical collar. (B) Measurement methods for evaluating mouth opening and Mallampati score with the cervical collar. (C) Measurement method for evaluating degree of neck extension with and without the cervical collar.

The Mallampati classification was determined by two different physicians. They discussed any disagreement in the scoring and then came to an agreement on a classification.

\section{Neck extension}

The angle of neck extension was evaluated in the supine position with the head in a neutral position and maximally extended. A reference line to assess the degree of the angle was determined 
using glasses fixed to the participant's head. Two photographs of each participant, with and without a cervical collar (neutral position and maximally extended position), were taken using a digital camera that was locked in place on a tripod. These photographs were mixed, and a photomontage was created using a computer. We assessed the angle by measuring the distance between the two reference lines drawn on the two photographs.

\section{Cervical collar application}

We used the Ambu Perfit ACE cervical collar (Ambu Inc., Ballerup, Denmark), which is commonly used in South Korea. ${ }^{10}$ The sizing and fitting of the collar was determined by two physicians according to the manufacturer's manual. First, one physician stabilized the participant's head and neck, gently holding the head and neck in the neutral alignment position. Second, the other physician adjusted the collar to the appreciate size and measured the distance between the lower border of the chin and the top of the shoulder. Finally, the cervical collar was placed on the volunteer.

\section{Definition}

We defined a difficult airway as the presence of any of the following parameters from previous studies: obesity, ${ }_{11}^{11} \mathrm{BMI} \geq 30 \mathrm{~kg} / \mathrm{m}^{2}$;

Table 1. Baseline characteristics of participants

\begin{tabular}{llc}
\hline Characteristics & Value \\
\hline Male/female & & $40(53) / 36(47)$ \\
Age $(\mathrm{yr})$ & $36 \pm 13$ \\
Height $(\mathrm{cm})$ & $168 \pm 9$ \\
Weight $(\mathrm{kg})$ & $64 \pm 13$ \\
Body mass index $\left(\mathrm{kg} / \mathrm{m}^{2}\right)$ & & $22.4 \pm 3$ \\
Neck collar size & Neckless & 0 \\
& Small & 25 \\
& Regular & 38 \\
& Tall & 13 \\
\hline
\end{tabular}

Values are represented as number $(\%)$, mean \pm standard deviation, or number.

Table 2. The LEMON assessment data

\begin{tabular}{llccc}
\hline \multicolumn{1}{l}{ Criteria } & & $\begin{array}{c}\text { No collar } \\
(n=76)\end{array}$ & $\begin{array}{c}\text { Collar } \\
(n=76)\end{array}$ & P-value \\
\hline E $\quad$ Mouth opening (cm) & & $4.3 \pm 0.5$ & $2.6 \pm 0.5$ & $<0.001$ \\
M $\quad$ Mallampati score & I & $33(43.4)$ & 0 & $<0.001$ \\
& II & $31(40.8)$ & $7(9.2)$ & \\
& III & $12(15.8)$ & $60(78.9)$ & \\
& IV & 0 & $9(11.8)$ &
\end{tabular}

N Neck extension $\left({ }^{\circ}\right) \quad 44.0 \pm 3.0 \quad 22.0 \pm 3.0 \quad<0.001$

Values are represented as mean \pm standard deviation or number $(\%)$. LEMON, look externally, evaluate 3-3-2, Mallampati score, obstruction, and neck mobility. mouth opening ${ }_{1}^{4}$ three fingerbreadths or less; modified Mallampati classification, ${ }^{4}$ class III or higher; or neck extension, ${ }^{12}<35^{\circ}$.

\section{Statistical analysis}

Measured data were analyzed using IBM SPSS Statistics ver. 20.0 (IBM Corp., Armonk, NY, USA). Continuous variables are presented as mean \pm standard deviation. Differences between the non-collar and collar groups were analyzed using the Student's paired t-test (normal distribution), Wilcoxon signed-rank test (non-normal distribution), sign test (ordinal variables), or McNemar test (categorical variables). Logistic regression analysis was conducted to determine which independent factors (among sex, age, BMI, and cervical collar size) were associated with difficult intubation. A Pvalue less than 0.05 was considered significant.

\section{RESULTS}

\section{Baseline characteristics and measurements}

Seventy-six volunteers participated, including 40 men (53\%) and 36 women (47\%). The mean age of the participants was $36 \pm 13$ years; mean height and weight were $168 \pm 9 \mathrm{~cm}$ and $64 \pm 13 \mathrm{~kg}$, respectively, and mean BMI was $22.4 \pm 3.0 \mathrm{~kg} / \mathrm{m}^{2}$. We used 0 neckless, 25 small, 38 regular, and 13 tall collars (Table 1). The measurement values for the simulation study are presented in Table 2 .

\section{Mouth opening}

Seventy-four participants (97.3\%) without a cervical collar had a mouth opening of three fingerbreadths. Only six participants (7.9\%) had a mouth opening of three fingerbreadths opening after cervi-

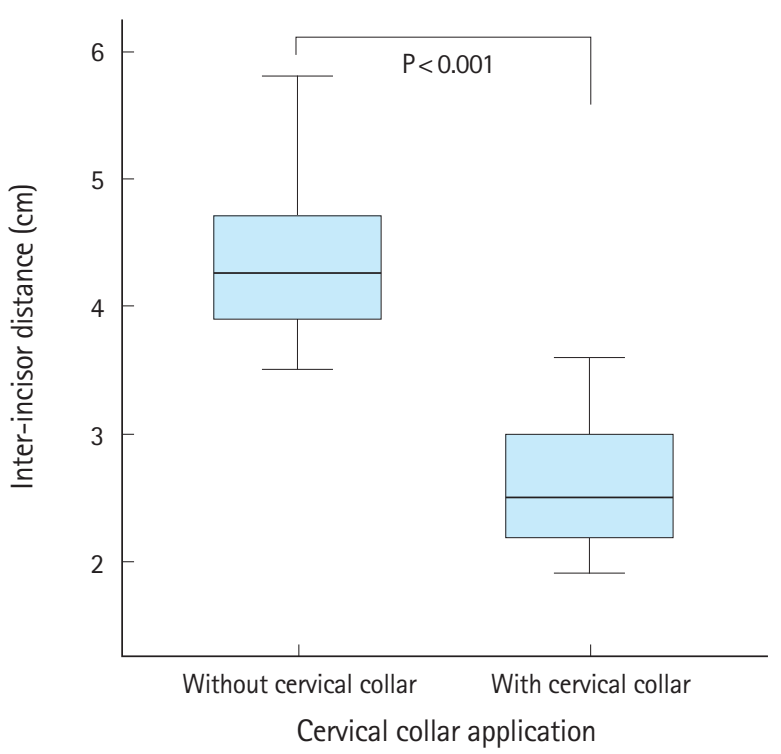

Fig. 3. Inter-incisor distance before and after cervical collar application. 


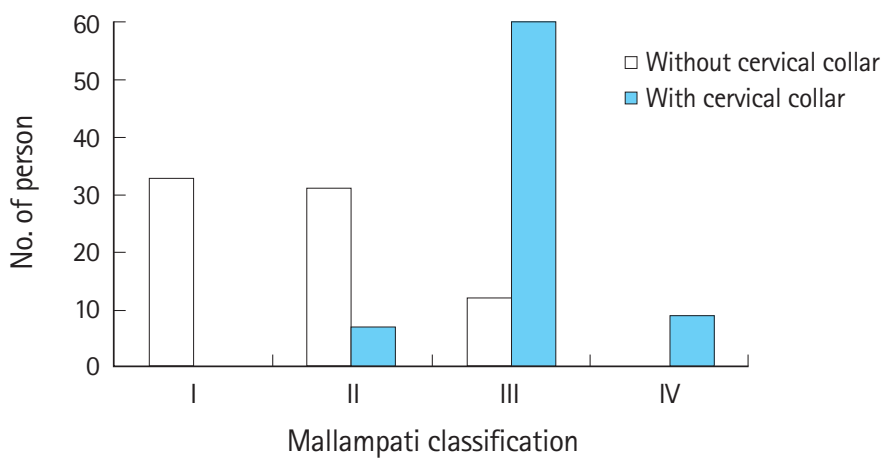

Fig. 4. Mallampati score before and after cervical collar application.

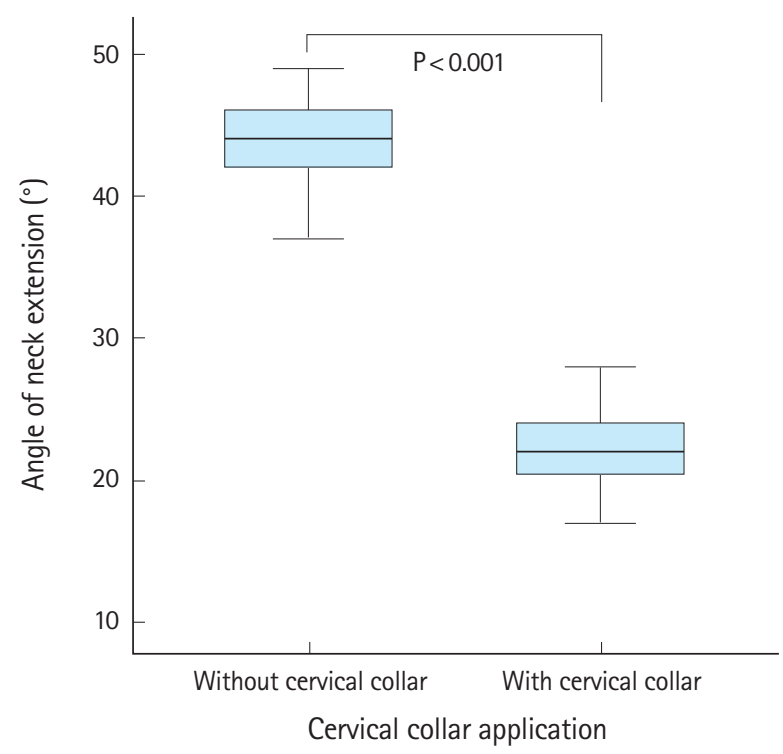

Fig. 5. Angle of neck extension before and after cervical collar application.

cal collar application. The mean inter-incisor distance significantly decreased from $4.3 \pm 0.5 \mathrm{~cm}$ to $2.6 \pm 0.5 \mathrm{~cm}$ after cervical collar application $(\mathrm{P}<0.001)$ (Fig. 3).

\section{Modified Mallampati classification}

Fifty-seven participants classified as I and II were changed to class III and IV after cervical collar application (16\% to 91\%) (Fig. 4).

\section{Neck extension}

The angle of neck extension significantly decreased from $44^{\circ}$ to $22^{\circ}$ after cervical collar application $(P<0.001)$ (Fig. 5).

\section{Anticipated difficult intubation}

A difficult airway was anticipated in 14 participants (18\%) not wearing a cervical collar, which increased to $76(100 \%)$ after cervical collar application (Table 3). Multiple logistic regression anal-
Table 3. Anticipated difficult intubation by the LEMON criteria

\begin{tabular}{llcc}
\hline \multicolumn{2}{l}{ Criteria } & $\begin{array}{c}\text { No collar } \\
(\mathrm{n}=76)\end{array}$ & $\begin{array}{c}\text { Collar } \\
(\mathrm{n}=76)\end{array}$ \\
\hline E & Incisor distance $<3$ finger breadths & $2(3)$ & $70(92)$ \\
$\mathrm{M}$ & Mallampati score $\geq$ class III & $12(16)$ & $69(91)$ \\
0 & Body mass index $\geq 30 \mathrm{~kg} / \mathrm{m}^{2}$ & $1(1)$ & $1(1)$ \\
$\mathrm{N}$ & Neck extension $<35^{\circ}$ & $1(1)$ & $76(100)$ \\
& Anticipated difficult airway & $14(18)$ & $76(100)$
\end{tabular}

Values are represented as number (\%).

LEMON, look externally, evaluate 3-3-2, Mallampati score, obstruction, and neck mobility.

ysis did not identify any particular risk factors (sex, age, BMI, and neck collar size) associated with a difficult airway.

\section{DISCUSSION}

A cervical collar is used to prevent neurological damage in individuals with head and neck injuries by limiting movement of the neck by external forces. ${ }^{2}$ However, it makes intubation difficult by limiting motion (flexion, extension, rotation, and lateral bending) and may increase the risk of hypoxemia because of difficult glottic visualization. ${ }^{13,14}$

A normal adult has a mouth opening that can accommodate three fingerbreadths in the center of the mouth, which is equivalent to $4-6 \mathrm{~cm}^{15}$ If the maximum mouth opening is less than 3 $\mathrm{cm}$, the patient is considered to have significant temporomandibular joint dysfunction. If it is less than $2.5 \mathrm{~cm}$, it is expected that the larynx will not be able to be visualized through conventional laryngoscopy. Lastly, if it is less than $2 \mathrm{~cm}$, the insertion of a Macintosh 3 or 4 blade and intubation with a laryngeal mask can be difficult, and an alternative method may be required. ${ }^{16,17} \mathrm{~A}$ cervical collar can cause limitations in mouth opening. According to Goutcher and Lochhead, ${ }_{1}^{18}$ the mouth opening decreased from $4.1 \pm 0.7 \mathrm{~cm}$ to $2.6 \pm 0.8 \mathrm{~cm}$ (Stiffneck collar), $2.9 \pm 0.9 \mathrm{~cm}$ (Miami collar), and $2.9 \pm 0.9 \mathrm{~cm}$ (Philadelphia collar) after applying collars to patients. Additionally, in a recent multicenter randomized controlled study, it was found that the mouth opening decreased from $4.6 \pm 0.7 \mathrm{~cm}$ to $2.3 \pm 0.3 \mathrm{~cm}$ after cervical collar application. ${ }^{19}$ Likewise, in our study, the mouth opening decreased from $4.3 \pm 0.5$ to $2.6 \pm 0.5 \mathrm{~cm}$, showing a significant decrease similar to that reported in previous studies. The mean inter-incisor distance in the cervical collar group in our study decreased to less than $3 \mathrm{~cm}$ (an expected difficult airway). In 39 participants (51\%), the distance was $2.5 \mathrm{~cm}$ or less (expected failure of conventional laryngoscope), and in seven participants (9\%), it was less than $2 \mathrm{~cm}$ (insertion of a Macintosh 3 or 4 blade or intubating with a laryngeal mask is difficult). According to these results, approximately 50\% of par- 
ticipants with a cervical collar were expected to fail direct conventional laryngoscopic intubation while wearing a cervical collar. Therefore, alternative methods, such as using novel intubating devices or MILS, should be considered in these types of cases.

The modified Mallampati classification is determined by the degree of mouth opening and size of the tongue and oral pharynx. ${ }^{9,20}$ However, with the cervical collar, it is expected that the limitations of mouth opening and movement of the tongue will result in a higher classification. Komatsu et al. ${ }^{21}$ reported that the Mallampati classification was higher in the case of cervical collar application. Similarly, in our study, the number of participants with a Mallampati class III or higher, which indicates an expected difficult airway, increased from 16\% to 91\% after cervical collar application. The number of participants with a class IV, which indicates a greater than 10\% failure of endotracheal intubation, increased from 0 to $9(12 \%)$.

The normal range of neck extension is $35^{\circ}$ or higher. Additionally, if this range is decreased by more than one-third, it is expected that intubation will be difficult. ${ }^{12}$ In previous studies on Western populations, the reduction rate was around $56 \%$ to $67 \%{ }^{22}$ In a similar study of Asian subjects, the reduction rate was $65 \%$ to $70 \% .{ }^{10}$ In our study, the range of extension without a cervical collar was $44^{\circ}$, which was reduced to $22^{\circ}(50 \%)$ after cervical collar application. Additionally, only one participant (1.3\%) in the non-collar group had a neck extension less than $35^{\circ}$, whereas all participants in the collar group (100\%) had a neck extension less than $35^{\circ}$ (range, $1.7^{\circ}$ to $2.8^{\circ}$ ), indicating that the cervical collar application itself is the main factor resulting in difficult airway management.

In our study, a difficult airway according to the LEMON criteria was observed in 14 of 76 participants (18.4\%) among the general population. However, after cervical collar application, this increased to $100 \%$ of 76 participants. Therefore, cervical collars, which are used to maintain alignment of the cervical spine and prevent neurologic damage, can increase problems with airway management. Interestingly, no studies have clearly shown suitable methods for intubating patients with a cervical collar.

It is well known that the use of MILS or the use of novel devices is recommended in guidelines for securing the airway in trauma victims with a cervical collar. ${ }^{23-25}$ However, there is much controversy about the superiority of these maneuvers or devices. MILS may not properly support full immobilization because of increases in pressure transmitted to the cervical spine by the laryngoscope. ${ }^{26}$ Moreover, MILS cannot be performed alone without skilled assistants. ${ }^{27}$ Novel devices take time for personnel to be trained in their use and are not always available in most emergency departments. ${ }^{5}$

Many studies on optimal intubating methods for patients in such cases mainly focused on the demonstration of superiority by comparing novel devices with conventional laryngoscopes. ${ }^{28} \mathrm{How}-$ ever, our study aimed to provide specific values on why the use of a conventional laryngoscope is difficult. Further research on the new maneuvers and novel devices is needed to overcome the difficulties presented in this study.

There were some limitations of our study. First, a limited number of participants volunteered for this study. Although the size of our population was relatively larger compared with that of similar studies, a study with a larger population is necessary. Second, the body measurements of Koreans do not represent those of the general population. However, this is also one of the strengths of this study, as there have not been any full-scale studies on Asian subjects. Lastly, we used only a cervical collar by Ambu Inc., and there is a large variety of cervical collars available. However, we focused on the efficacy of neck immobilization rather than comparing the different types of collars. Therefore, we used one of the most widely used products in Korea. In the future, it would be an interesting research topic to determine what differences may exist in the LEMON criteria between various cervical collars.

In the present simulation study, all measured values (mouth opening, modified Mallampati classification, and neck extension) of the LEMON criteria worsened significantly with cervical collar application. Additionally, a difficult airway was predicted in 18.4\% and 100\% of cases before and after cervical collar application, respectively.

An additional study of the use of cervical collars and novel intubating devices is necessary.

\section{CONFLICT OF INTEREST}

No potential conflict of interest relevant to this article was reported.

\section{REFERENCES}

1. ATLS Subcommittee; American College of Surgeons' Committee on Trauma; International ATLS working group. Advanced trauma life support (ATLS): the ninth edition. J Trauma Acute Care Surg 2013;74:1363-6.

2. Holley J, Jorden R. Airway management in patients with unstable cervical spine fractures. Ann Emerg Med 1989;18:1237-9.

3. Hills MW, Deane SA. Head injury and facial injury: is there an increased risk of cervical spine injury? J Trauma 1993;34:54953.

4. American Society of Anesthesiologists Task Force on Management of the Difficult Airway. Practice guidelines for manage- 
ment of the difficult airway: an updated report by the American Society of Anesthesiologists Task Force on Management of the Difficult Airway. Anesthesiology 2003;98:1269-77.

5. Kim JW, Lee KR, Hong DY, Baek KJ, Lee YH, Park SO. Efficacy of various types of laryngoscope (direct, Pentax Airway Scope and GlideScope) for endotracheal intubation in various cervical immobilisation scenarios: a randomised cross-over simulation study. BMJ Open 2016;6:e011089.

6. Reed MJ, Dunn MJ, McKeown DW. Can an airway assessment score predict difficulty at intubation in the emergency department? Emerg Med J 2005;22:99-102.

7. Mahmoodpoor A, Soleimanpour $\mathrm{H}$, Nia KS, et al. Sensitivity of palm print, modified mallampati score and 3-3-2 rule in prediction of difficult intubation. Int J Prev Med 2013;4:1063-9.

8. Shiga T, Wajima Z, Inoue T, Sakamoto A. Predicting difficult intubation in apparently normal patients: a meta-analysis of bedside screening test performance. Anesthesiology 2005;103: 429-37.

9. Mallampati SR, Gatt SP, Gugino LD, et al. A clinical sign to predict difficult tracheal intubation: a prospective study. Can Anaesth Soc J 1985;32:429-34.

10. Choi HS, Park HK, Hong HP, Kim MC, Ko YG. A comparison of efficacy of two cervical orthoses in Koreans. J Korean Soc Emerg Med 2004;15:213-21.

11. WHO Expert Consultation. Appropriate body-mass index for Asian populations and its implications for policy and intervention strategies. Lancet 2004;363:157-63.

12. Bellhouse $C P$, Dore $C$. Criteria for estimating likelihood of difficulty of endotracheal intubation with the Macintosh laryngoscope. Anaesth Intensive Care 1988;16:329-37.

13. Heath KJ. The effect of laryngoscopy of different cervical spine immobilisation techniques. Anaesthesia 1994;49:843-5.

14. Majernick TG, Bieniek R, Houston JB, Hughes HG. Cervical spine movement during orotracheal intubation. Ann Emerg Med 1986;15:417-20.

15. Finucane BT, Santora AH, Tsui B. Principles of airway management. New York, NY: Springer; 2003.

16. Posselt U. Physiology of occlusion and rehabilitation. Oxford, UK: Blackwell Scientific; 1968.

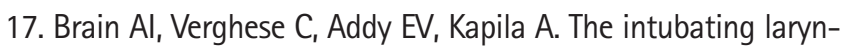

geal mask. I. Development of a new device for intubation of the trachea. Br J Anaesth 1997;79:699-703.

18. Goutcher CM, Lochhead V. Reduction in mouth opening with semi-rigid cenvical collars. Br J Anaesth 2005;95:344-8.

19. Kleine-Brueggeney M, Greif R, Schoettker P, Savoldelli GL, Nabecker $\mathrm{S}$, Theiler LG. Evaluation of six videolaryngoscopes in 720 patients with a simulated difficult airway: a multicentre randomized controlled trial. Br J Anaesth 2016;116:670-9.

20. Walls RM, Murphy MF. Manual of emergency airway management. Philadelphia, PA: Lippincott Williams \& Wilkins; 2008.

21. Komatsu R, Nagata O, Kamata K, Yamagata K, Sessler DI, Ozaki M. Intubating laryngeal mask airway allows tracheal intubation when the cervical spine is immobilized by a rigid collar. Br J Anaesth 2004;93:655-9.

22. Zhang S, Wortley M, Clowers K, Krusenklaus JH. Evaluation of efficacy and 3D kinematic characteristics of cervical orthoses. Clin Biomech (Bristol, Avon) 2005;20:264-9.

23. Criswell JC, Parr MJ, Nolan JP. Emergency airway management in patients with cervical spine injuries. Anaesthesia 1994;49: 900-3.

24. Henderson JJ, Popat MT, Latto IP, Pearce AC; Difficult Airway Society. Difficult Airway Society guidelines for management of the unanticipated difficult intubation. Anaesthesia 2004; 59:675-94.

25. Deasy C, Cameron P. Routine application of cervical collars: what is the evidence? Injury 2011;42:841-2.

26. Santoni BG, Hindman BJ, Puttlitz CM, et al. Manual in-line stabilization increases pressures applied by the laryngoscope blade during direct laryngoscopy and orotracheal intubation. Anesthesiology 2009;110:24-31.

27. Lennarson PJ, Smith DW, Sawin PD, Todd MM, Sato Y, Traynelis VC. Cervical spinal motion during intubation: efficacy of stabilization maneuvers in the setting of complete segmental instability. J Neurosurg 2001;94:265-70.

28. Gawlowski P, Smereka J, Madziala M, Szarpak L, Frass M, Robak 0. Comparison of the Macintosh laryngoscope and blind intubation via the iGEL for intubation with cervical spine immobilization: a randomized, crossover, manikin trial. Am J Emerg Med 2017;35:484-87. 